$\xi_{p}$

\title{
Thermodynamic Studies of Bovine Serum Albumin (BSA) Adsorption on Nylon Membrane
}

\author{
N. Ideris ${ }^{1}$, A.M. Roslan ${ }^{2}$ \\ Faculty of Chemical Engineering, Universiti Teknologi MARA, 40450 Shah Alam, Selangor, Malaysia \\ *Corresponding author E-mail: norhidayah7229@salam.uitm.edu.my
}

\begin{abstract}
The aim of this study was to investigate the nylon membrane's characteristics and thermodynamic aspects for adsorption of Bovine Serum Albumin (BSA) as a model protein on nylon membrane. The morphology characteristics analyzed by FESEM and wetting and weighting technique showed the nylon membrane possessed micro-pore size $(0.159 \pm 0.039 \mu \mathrm{m})$ with high porosity $(74.2820 \pm 0.0411 \%)$ respectively. Thermodynamic studies indicated that the adsorption reaction was endothermic with positive value of standard enthalpy $\left(\Delta \mathrm{rH}_{\theta}=107.7 \mathrm{~kJ} / \mathrm{mole}\right)$ and dominated by chemical adsorption. The results were supported with the analysis of functional groups of the nylon membrane with FTIR-ATR. Bands corresponding to the NH bonds stretching were generally detected in the $3500-3100 \mathrm{~cm}^{-1}$ range The existence of $\mathrm{C}=\mathrm{O}$ stretching vibration of carbonyl group was further confirmed with the observation of peak at $1632.42 \mathrm{~cm}^{-1}$. The water contact angle analysis showed the hydrophilicity nature of nylon membrane with contact angle of $55.6^{\circ}$. These findings are expected to be used in the modification of nylon membrane for an optimum adsorption of protein.
\end{abstract}

Keywords: Nylon membrane, BSA, morphology, thermodynamic

\section{Introduction}

Biomaterial is defined as a material placed in contact with biological fluids and it is expected to function with a desirable host response in specific applications, without any desirable effects. Recently, the use of polymeric membrane as one of the selective biomaterials has gained a lot of attention for its versatility and biocompatibility properties [1]. Besides, most of the membrane can be operated at low temperature and pressure, thereby minimizing the denaturation and degradation of biological products [2].

Some examples of the usage of membrane as biomaterial in biomedical field are hemodialysis [3], bone regeneration [4] and diagnostic-kit [5]. In the latter, diagnostic-kit are favorable in overcoming the issues of scarcity of medical resources such as highly trained specialists and advanced diagnostic equipment. It is sensitive, affordable and efficient tools to assist untrained medical workers and offset the unavailability of non-portable high-end technology in rural area. Usually, diagnostic kits are functionally based on the concept of immunoassays, such as those in the initial screens of typhoid, malaria and tuberculosis. Another example would be the very commonly available pregnancy test strip [6].

The assembly of the diagnostic-kit can be divided into two parts; the immunoagents extraction and membrane selection. Membranes such as nitrocellulose [7], poly (vinylidenefluoride) [8], nylon [9] and cellulose acetate [10] have been used in the preparation of diagnostic-kit. These diagnostic kit might apply the concept of filtration, absorption and adsorption as the working mechanism. However, different application will require different working mechanism and different characteristics of membrane. Thus, it is important to analyze some insights about the interaction between the protein molecule and membrane interface via thermodynamic studies.

\section{Methodology}

\subsection{Membrane characterization}

The pore size distributions of the nylon membranes were observed by using scanning electron microscopy, SEM (TM3000, Hitachi, Japan) at $15 \mathrm{kV}$ and 5000x magnification. The samples were cut into $10 \mathrm{~mm} \times 10 \mathrm{~mm}$ and coated with Au-Pd alloy to reduce the beam penetration. The images were then analyzed using ImageJ for the pore size distribution. The measurement of porosity by using wetting and weighting technique has been discussed elsewhere [6], with specific gravity of water $(1.0 \mathrm{~g} / \mathrm{cm} 3)$ and specific gravity of nylon $(1.12 \mathrm{~g} / \mathrm{cm} 3)$. Then, for the analysis of functional groups, the nylon membranes were cut into $20 \mathrm{~mm}$ diameter and examined by using ATR-FTIR (Spectrum One, Perkin Elmer, US) at $4 \mathrm{~cm}-1$ resolutions at $45^{\circ}$ incident angle. For measurement of water contact angle, sessile drop technique was performed using contact angle analyzer (VCA3000, ASTInc, US) at ambient temperature.

\subsection{Protein adsorption and thermodynamic studies}

The adsorption experiments were carried out by preparing $3 \mathrm{~mL}$ of BSA protein solution, having an initial concentration, $\mathrm{C}_{\mathrm{i}}$ of 0.5 $\mathrm{mg} / \mathrm{ml}$. The membrane samples were cut into $2 \mathrm{~cm} \times 2 \mathrm{~cm}$ and completely immersed in the test tube containing $3 \mathrm{~mL}$ of BSA solution. The test tubes were then replaced in the water bath (MAXturday30, Wisd, Korea) at $300 \mathrm{~K}$ for 3 hours. Unbound BSA on the surface of the membrane was washed with distilled water. Each membrane sample was transferred into a test tube and $2 \mathrm{~mL}$ of bicinchoninic acid-working reagent was added. The amount of BSA adsorbed on membrane, $\mathrm{C}_{\mathrm{m}}$ was measured using 
UV spectrophotometer at $562 \mathrm{~nm}$ wavelength. The adsorption experiments were repeated at $305 \mathrm{~K}, 310 \mathrm{~K}, 313 \mathrm{~K}$ and $318 \mathrm{~K}$.

The thermodynamic properties such as standard enthalpy $\left(\Delta_{\mathrm{r}} \mathrm{H}_{\mathrm{o}}\right)$, standard Gibbs free energy $\left(\Delta_{\mathrm{r}} \mathrm{G}_{\mathrm{o}}\right)$ and standard entropy $\left(\Delta_{\mathrm{r}} \mathrm{S}_{\mathrm{o}}\right)$ were calculated by using the data of protein adsorption at different temperatures. The equation used for the determination of thermodynamic parameters were shown below:

$\mathrm{C}_{\mathrm{e}}=\mathrm{C}_{\mathrm{i}}-\mathrm{C}_{\mathrm{m}}$

$\mathrm{K}=\left(\mathrm{C}_{\mathrm{i}}-\mathrm{C}_{\mathrm{e}}\right) / \mathrm{C}_{\mathrm{e}}$

$\Delta_{\mathrm{r}} \mathrm{G}_{\mathrm{o}}=-\mathrm{RT} \ln (\mathrm{K})$

$\ln (\mathrm{K})=-\Delta_{\mathrm{r}} \mathrm{H}_{\mathrm{O}} / \mathrm{RT}+\Delta_{\mathrm{r}} \mathrm{S}_{\mathrm{O}} / \mathrm{R}$

where $\mathrm{C}_{\mathrm{e}}$ is the protein concentration at equilibrium, $\mathrm{R}$ is the gas constant $(8.314 \mathrm{~J} / \mathrm{mol} . \mathrm{K})$ and $\mathrm{T}$ is the temperature $(\mathrm{K})[11]$.

\section{Results and Discussion}

The SEM images (Figure 1) show the upper and bottom part view of nylon membrane at 5000x magnification. It was observed that nylon membrane possessed a symmetrical structure with almost identical morphology. The pore size distribution for upper and bottom surface of the membrane was calculated using ImageJ software and the results are $0.159 \pm 0.039 \mu \mathrm{m}$ and $0.181 \pm 0.039 \mu \mathrm{m}$ respectively. The pore size of this membrane sample falls within the range of micro-pore size membrane. The porosity (pore volume) value obtained from the wetting and weighting method is $74.2820 \pm 0.0411 \%$, thus, the nylon membrane sample was considered to have high membrane porosity. Theoretically, a combination of smaller pored membrane with high porosity would be desirable as a potential capture agent, as it would be expected to offer larger surface area for protein adsorption [12], [6]

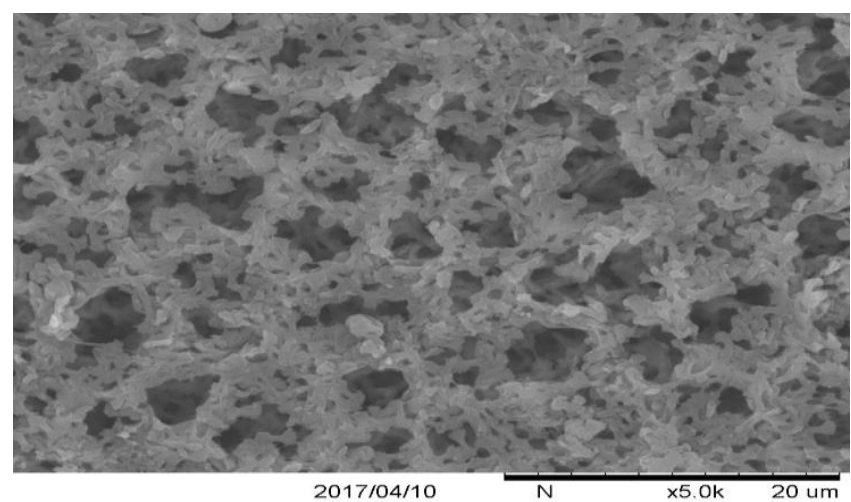

Muzakkir-5000

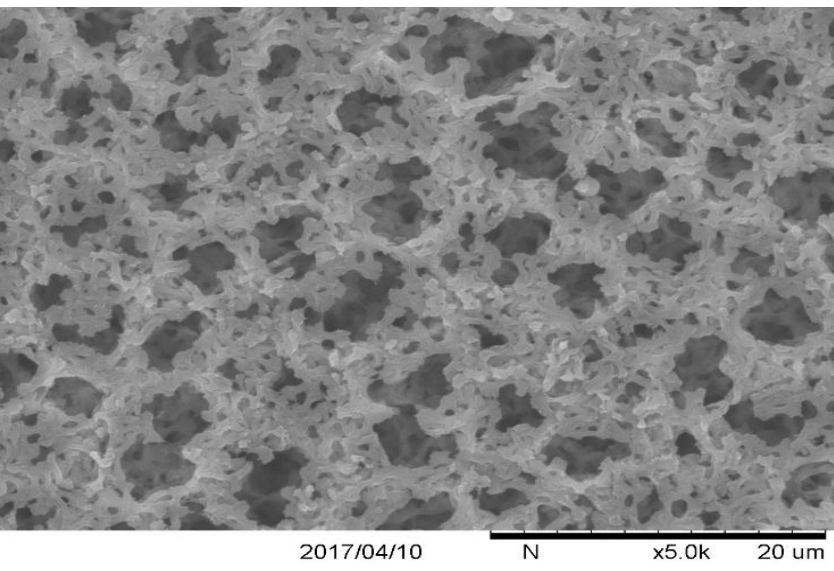

Muzakkir-5000

Fig. 1: The SEM images of surface (a) and bottom (b) of nylon membrane
Besides measuring the amount of protein adsorbed on membrane interface, it is important to evaluate the possible interaction involved between the protein molecule and membrane to ensure the robustness and flexibility of the developed diagnostic kits in real application. Thermodynamic studies were conducted at different temperatures for further analysis of the interaction involved.

Temperature is considered a key factor in the adsorption process. This experiment was conducted in various ranges of temperature $(300 \mathrm{~K}, 305 \mathrm{~K}, 310 \mathrm{~K}, 313 \mathrm{~K}, 318 \mathrm{~K})$ show the trend of increasing protein adsorption as temperature increased, up to $310 \mathrm{~K}$ (Figure 2). However, the adsorption starts to decrease at temperature of $313 \mathrm{~K}$ and above which is believed as the effect of denaturation process.

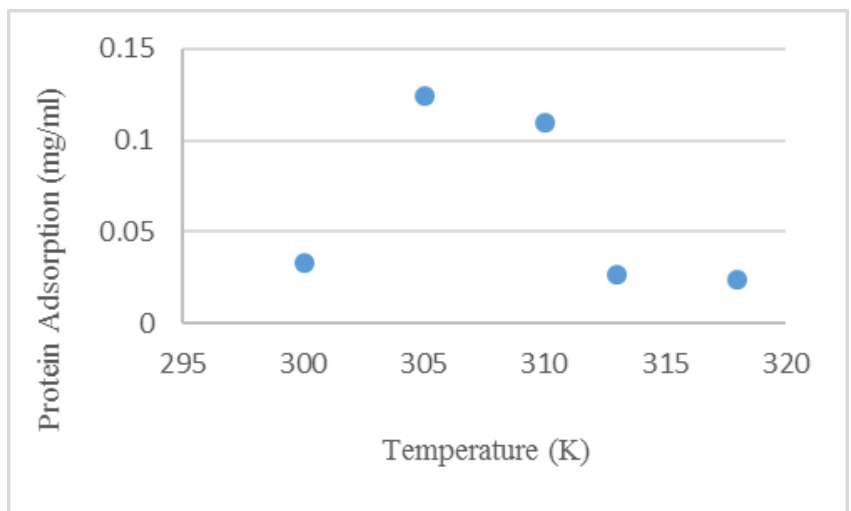

Fig. 2: Protein adsorption at respective temperature

The thermodynamic parameters such as standard enthalpy $(\Delta \mathrm{rHo})$, standard Gibbs free energy $(\Delta \mathrm{rGo})$ and standard entropy $(\Delta \mathrm{rSo})$ during the adsorption of protein was ascertained by drawing Van't Hoff plots (ln K vs 1/T values) of BSA adsorption on nylon membrane (Figure 3). As an effect from the denaturation process at 313 $\mathrm{K}$ and above, the data was excluded in the thermodynamic studies. From the plot, the value of $\Delta \mathrm{rHo}$ was $107 \mathrm{~kJ} / \mathrm{mole}$ with the positive value implied endothermic reaction involved during the process of adsorption. Thus, the protein adsorption is predominantly driven by chemisorption as the value of $\Delta \mathrm{rHo}$ was between $40-120$ $\mathrm{kJ} /$ mole, rather than common physical adsorption [13], [11].

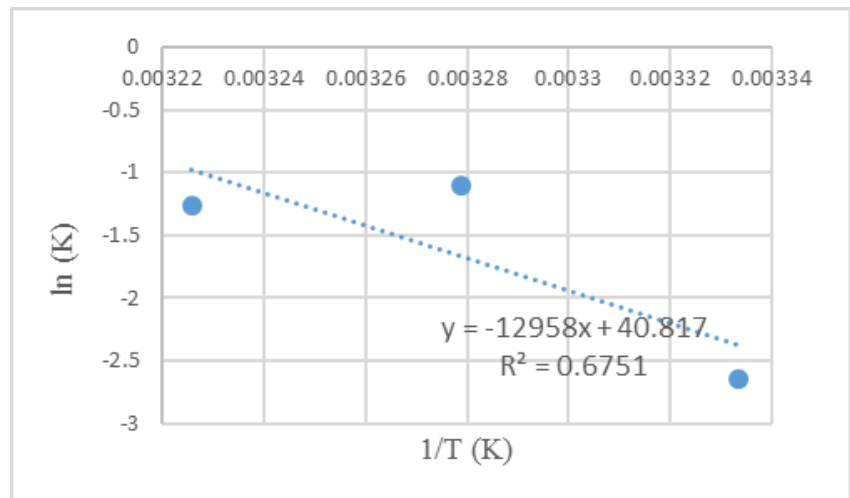

Fig. 3: Van't Hoff plots of BSA adsorption onto nylon membrane

The results were supported from the characterization of functional groups by using FTIR-ATR (Figure 4). Peak at $1632.42 \mathrm{~cm}-1$ was ascribed to the $\mathrm{C}=\mathrm{O}$ stretching vibration of carbonyl group present in nylon membrane while peak at $3300.12 \mathrm{~cm}-1$ was ascribed to the N-H stretching vibration of amino groups. It was hypothesized that chemisorption occurs between the protein and nylon membrane was contributed by hydrogen bonding between the amino group of protein and carbonyl group of nylon membrane, and vice versa. Therefore, it was observed that the peak of free $\mathrm{C}=\mathrm{O}$ stretching vibration that normally appeared at $1700 \mathrm{~cm}$ 1, is barely visible in Figure 4 and shifted to $1632.42 \mathrm{~cm}-1$. Generally, hydrogen bonds are weaker than covalent bonds but they 
are much stronger than van der Waals forces that facilitate physical adsorption [14], [15].

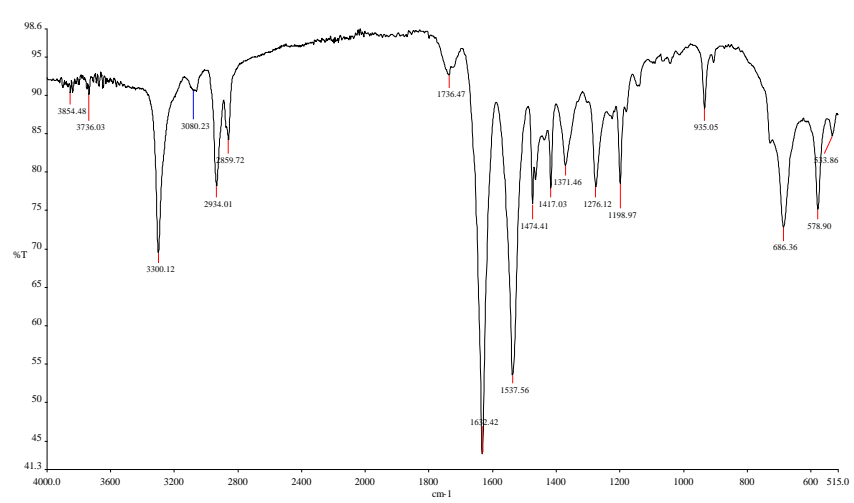

Fig. 4: FTIR-ATR spectra for nylon membrane

Besides, a test on water contact angle showed that the nylon membrane is hydrophilic with angle measurement of $55.6^{\circ}$ (Figure 5). It was generally known that a contact angle below than $90^{\circ}$ is acceptable as a hydrophilic material, whereas more than $90^{\circ}$ is a hydrophobic material [16]. Thus, physical adsorption contributed by hydrophobic interaction might be insignificant because of the hydrophilicity of nylon membrane and hydrophobicity of BSA. Another possible physical adsorption such as electrostatic interaction might be significant, however further analysis on streaming potential on nylon membrane before and after protein adsorption is required. The electrostatic interaction will pre-dominate the protein-membrane interaction if the membrane surface is hydrophilic. However, this condition was highly dependable on the charge of the membrane itself and the $\mathrm{pH}$ of the protein solution prior to adsorption process. On the other hand, the adsorption of BSA would reach its best at isoelectric point (IEP). At the zero charge (IEP), there will be no competition between protein molecules and it will form a compact layer formation of BSA molecules on the nylon surface. The compact layer would promote shorter interaction due to shorter range between protein molecule and nylon membrane surface [17].

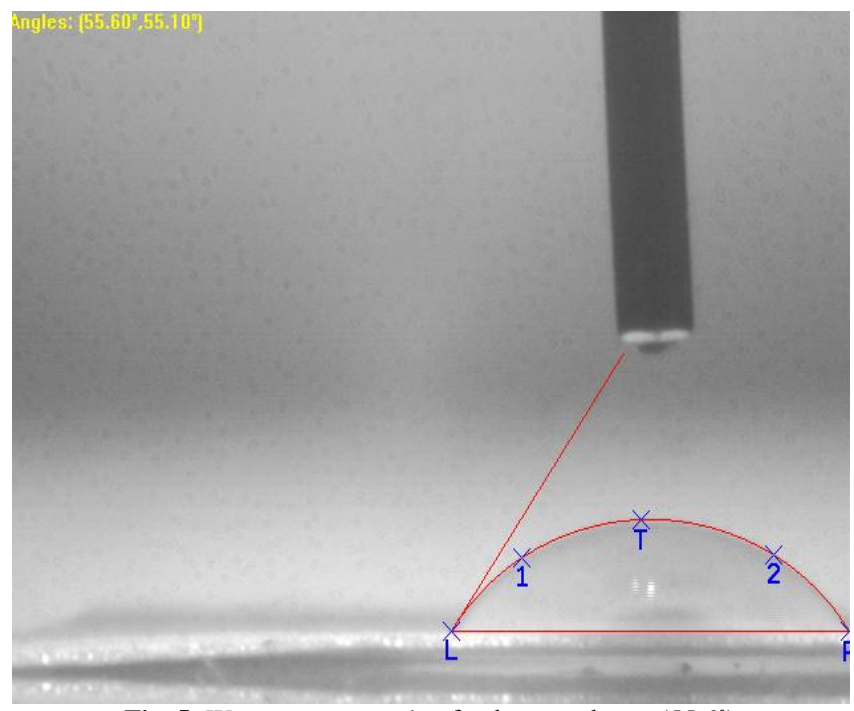

Fig. 5: Water contact angle of nylon membrane $\left(55.6^{\circ}\right)$

In addition, the value of standard entropy $(\Delta \mathrm{rSo})$ obtained from the Van't Hoff plots was $339.35 \mathrm{~J} / \mathrm{mol}$.K. The positive value reflects the distribution of BSA adsorbed on the nylon membrane was more chaotic than that in aqueous solution. The change in standard Gibbs free energy $(\Delta \mathrm{rGo})$ were further calculated and the results were $6.609,2.813$ and $3.362 \mathrm{~kJ} / \mathrm{mol}$ at $300 \mathrm{~K}, 305 \mathrm{~K}$ and $310 \mathrm{~K}$, respectively. All positive signs of $\Delta \mathrm{rGo}$ indicating that protein adsorption was feasible but not spontaneous [18].

\section{Conclusion}

In this study, nylon membrane was a symmetrical membrane with micro-pore size range. The porosity of the membrane is considered as high with $74.2820 \pm 0.0411 \%$. From the analysis of thermodynamic studies, it was concluded that hydrogen bonding was a possible dominant interaction between the protein molecules and nylon membrane. The results were supported by the measurement of functional groups for $\mathrm{NH}$ bonds stretching and $\mathrm{C}=\mathrm{O}$ stretching vibration. The hydrophilic nature of nylon membrane (water contact angle of $55.6^{\circ}$ ) suggested the possibility of electrostatic interaction at right $\mathrm{pH}$ medium. However, further elaborated studies needed to prove the clear mechanism of protein adsorption onto nylon membrane.

\section{Acknowledgement}

The authors acknowledged Universiti Teknologi MARA (600IRMI/MyRA5/3/LESTARI (0106/2016) for financial support.

\section{References}

[1] J. Marchand-Brynaert, 2006. Polymer membranes. In: Hubbard, A.T. (ed) Encyclopedia of Surface and Colloid Science. Boca Raton: Taylor \& Francis.

[2] C. Charcosset "Membrane processes in biotechnology: An overview" Biotechnology Advances Volume 24, Pages 482-492, 2006.

[3] V. Hoseinpoura, A. Ghaeeb, V. Vatanpourc, N. Ghaemia "Surface modification of PES membrane via aminolysis and immobilization of carboxymethylcellulose and sulphated carboxymethylcellulose for hemodialysis" Carbohydrate Polymers Volume 188, Pages $37-$ 47, February 2018.

[4] D. Huang, L. Niu, J. Li, J. Du, Y. Wei, Y. Hu, X. Lian, W. Chen, K Wang "Reinforced chitosan membranes by microspheres for guided bone regeneration" Journal of Mechanical Behavior and Biomedical Materials Volume 81, Pages 195-201, March 2018.

[5] P. Afshari, N. Abolfathi "A novel method for blood-typing using nitrocellulose" Biomedical Chromatography Volume 31, Issue 7, January 2017.

[6] A.L. Ahmad, N. Ideris, B.S. Ooi, S.C. Low, A. Ismail "Impact of membrane pore structure on protein detection sensitivity of affinitybased immunoassay" Polish Journal of Chemical Technology Volume 18, Issue 2, Pages 97-103, 2016.

[7] T. Tominaga "Rapid detection of Klebsiella pneumoniae, Klebsiella oxytoca, Raoultella ornithinolytica and other related bacteria in food by lateral-flow test strip immunoassays" Journal of Microbiological Methods Volume 147, Pages 43-49, March 2018.

[8] D. Chen, C. Wang, W. Chen, Y. Chen, J.X.J. Zhang "PVDF-Nafion nanomembranes coated microneedles for in vivo transcutaneous implantable glucose sensing" Biosensors and Bioelectronics Volume 74, Pages 1047-1052, July 2015.

[9] M. Mason, E. Longo, M. Scampicchio "Monitoring of glucose in beer brewing by a carbon nanotubes based nylon nanofibrous biosensor" Journal of Nanomaterials Volume 2016, May 2016.

[10] K. Nielsen, W.L. Yu, L. Kelly, J. Williams, A. Dajer, E. Gutierrez, G. Ramirez Cruz, T. Renteria, R. Bermudez, J. Algire "Validation and field assessment of a rapid lateral flow assay for detection of bovine antibody to Anaplasma marginale" Journal of Immunoassay and Immunochemistry Volume 30, Issue 3, Pages 313-321, July 2009.

[11] F. Qi, Y. Cao, M. Wang, F. Rong, Q. Xu "Nylon 6 electrospun nanofibers mat as effective sorbent for the removal of estrogens: kinetic and thermodynamic studies" Nanoscale Research Letters Volume 9, Pages 353-363, 2014.

[12] R.W. Baker, Membrane Technology, in Encyclopedia of Polymer Science and Technology, H.F. Mark, Editor 2003, A John Wiley \& Sons Publication: New Jersey.p. 184-249.

[13] M. Alkan, O. Demirbas, S. Celikcapa, M. Dogan "Sorption of acid red 57 from aqueous solution onto sepiolite" Journal of Hazardous Materials B116, Pages 135-145, 2004.

[14] J. Han, W. Qiu, J. Hu, W. Gao "Chemisorption of estrone in nylon microfiltration membranes: Adsorption mechanism and potential use for estrone removal from water" Water Research Volume 46, Pages 873-881, December 2011. 
[15] M. J. F. Jasni, M. Arulkumar, P. Sathishkumar, A. R. M. Yusoff, N. A. Buang, F. L. Gu " Electrospun nylon 6,6 membrane as a reusable nano-adsorbent for bisphenol A removal: Adsorption performance and mechanism" Journal of Colloid and Interface Science Volume 508, Pages 591-602, August 2017.

[16] Adamson, A.W. (1990). Physical Chemistry of Surfaces, New York, John Wiley \& Sons, Ltd.

[17] S. C. Low, R. Shaimi, Y. Thandaithabany, J. K. Lim, A. L. Ahmad, A. Ismail "Electrophoretic interactions between nitrocellulose membranes and proteins: Biointerface analysis and protein adhesion properties" Colloids and Surfaces B: Biointerfaces Volume 110, Pages 248-253, May 2013.

[18] Y. Zhou, Z. Wang, Q. Zhang, X. Xi, J. Zhang, W. Yang "Equilibrium and thermodynamic studies on adsorption of BSA using PVDF microfiltration membrane" Desalination Volume 307, Pages 61-67, September 2012 